\title{
RANCANG BANGUN APLIKASI PEMASARAN ELEKTRONIK BERBASIS AUGMENTED REALITY MENGGUNAKAN METODE WATERFALL
}

\author{
Yogi Nugroho \\ Program Pascasarjana Teknik Informatika \\ Universitas Trilogi \\ email : yoginugroho@trilogi.ac.id \\ Jl. Taman Makam Pahlawan No. 1, Kalibata, Jakarta 12760, Indonesia
}

\begin{abstract}
At this time the development of technology in the industry, especially electronics is growing rapidly. Many companies are competing to market their products in various ways in order to attract the attention of consumers. Today's electronic marketing methods generally use offline media such as brochures and magazines that feature two-dimensional images for more economic reasons. However, this certainly makes consumers who see it become dissatisfied and uninterested because of its limited appearance and lack of full depiction. From this problem the Augmented Reality method for electronic marketing with $3 D$ brochures is needed so that consumers get full information from the display of electronic products offered. In this study the authors made an electronic marketing application based on Augmented Reality using the waterfall method as the approach.
\end{abstract}

Kata kunci: Electronics, Augmented Reality, Marketing, Waterfall.

\begin{abstract}
Abstrak
Pada saat ini perkembangan teknologi di industri khususnya elektronik sedang berkembang pesat. Banyak perusahaan yang sedang berlomba-lomba untuk memasarkan produknya dengan berbagai cara agar dapat menarik perhatian konsumen. Metode pemasaran elektronik saat ini umumnya menggunakan media offline seperti brosur dan majalah yang menampilkan gambar dua dimensi dengan alasan lebih ekonomis. Namun, hal ini tentunya membuat konsumen yang melihatnya menjadi tidak puas dan tidak tertarik karena tampilannya terbatas dan kurangnya penggambaran secara penuh. Dari permasalahan ini diperlukan metode Augmented Reality untuk pemasaran elektronik dengan brosur secara 3D agar konsumen mendapatkan informasi secara penuh dari tampilan produk elektronik yang ditawarkan. Dalam penelitian ini penulis membuat aplikasi pemasaran elektronik berbasis Augmented Reality menggunakan metode waterfall sebagai pendekatannya.
\end{abstract}

Kata kunci: Elektronik, Augmented Reality, Pemasaran, Waterfall.

\section{PENDAHULUAN}

Perkembangan industri elektronik di Indonesia saat ini sudah sangat berkembang pesat mengikuti perkembangan zaman. Salah satu faktor penting dalam sebuah perusahaan adalah marketing atau penjualan. Teknik marketing yang digunakan saat ini adalah menggunakan media 
offline berupa brosur dan majalah yang menampilkan gambar dua dimensi produk yang ditawarkan. Namun teknik ini masih memiliki kekurangan seperti kurangnya penggambaran secara penuh dari bentuk produk yang ditawarkan, sehingga konsumen yang melihatnya menjadi tidak puas dan mengurangi daya tarik konsumen (Wulandari et al., n.d.). Maka dari permasalahan tersebut peneliti membuat media pemasaran menggunakan Augmented Reality dengan brosur secara 3D.

Dalam penelitian ini penulis membuat Augmented reality menggunakan software Unity3D dan Vuforia SDK yang mengubah gambar 2D menjadi gambar 3D secara real-time pada saat produk di scan menggunakan kamera android di dalam aplikasi yang akan dibuat.

Tujuan penelian ini yaitu menyediakan solusi atau inovasi dalam pemasaran produk agar para perusahaan dapat mempromosikan produknya dengan lebih atraktif. Yakni dengan menggunakan aplikasi Augmented Reality dengan bantuan software Unity3D sebagai alat bantu promosi yang mengubah gambar dalam bentuk 2D menjadi gambar 3D secara realtime dengan media brosur dengan men-scan marker berupa barcode (Maulana, 2017).

\section{METODOLOGI PENELITAN}

Rancang bangun aplikasi dalam penelitian ini menggunakan metode Waterfall untuk pendekatannya. Metode air terjun atau yang disebut metode Waterfall dinamakan siklus hidup klasik (classic life circle). dimana hal ini menggambarkan pendekatan yang sistematis dan juga berurutan pada pengembangan perangkat lunak, dimulai dengan spesifikasi kebutuhan pengguna lalu berlanjut melalui tahapan-tahapan perencanaan (planning), permodelan (modeling), konstruksi (construction), serta penyerahan sistem ke para pelanggan/pengguna (deployment), yang diakhiri dengan dukungan pada perangkat lunak lengkap yang dihasilkan (Anggratama, 2016).Tahapan tahapan dari metode waterfall adalah sebagai berikut.

\subsection{Requirement Analisis}

Pada tahap ini pengembang sistem diperlukan komunikasi yang bertujuan untuk memahami perangkat lunak yang diharapkan oleh pengguna dan batasan perangkat lunak tersebut. Dalam tahapan ini penulis menggunakan device untuk menyelesaikan masalah yang di hadapi oleh user. Hal yang dibutuhkan antara lain adalah :

A. Kebutuhan hardware dan software

- Personal Computer (PC)

- Laptop Dell Insipiron

- Processor intel core i3

- Ram 4 GB

- Windows 10 64-bit

- Unity3D

- Vuforia SDK

- $\quad$ Adobe Photoshop CS6

B. Kebutuhan Sistem

- Tampilan peralatan elektronik 
- Tampilan brosur peralatan elektronik

- Tampilan scan QR barcode

\subsection{System Design}

Desain Sistem membantu dalam menentukan perangkat keras (hardware) dan sistem persyaratan dan juga membantu dalam mendefinisikan arsitektur sistem secara keseluruhan. Pada tahap ini penulis menggunakan Diagram Flowchart sebagai berikut:

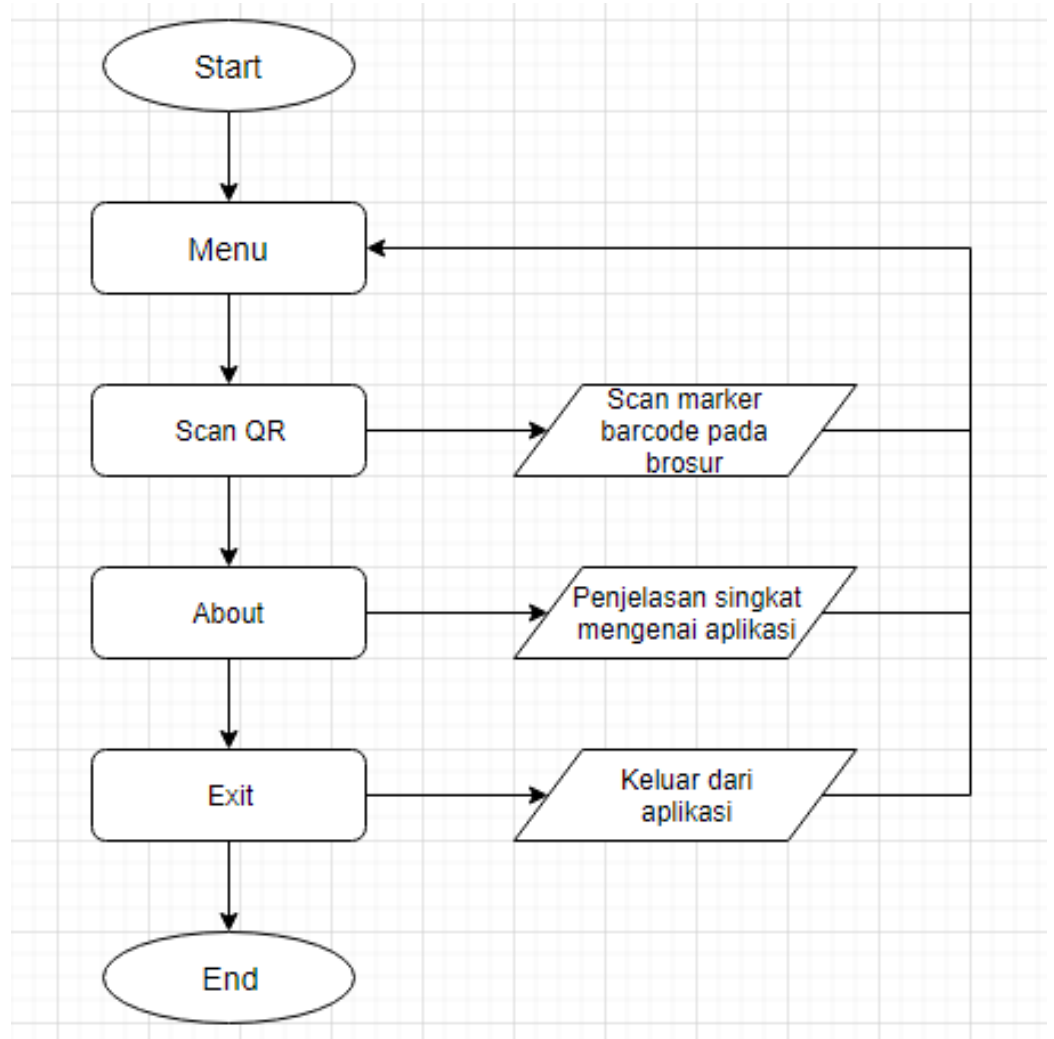

Gambar 1. Diagram Flowchart

Gambar diatas merupakan alur dari aplikasi tersebut. Dimulai dari menu yang dan terdapat 3 pilihan yaitu Scan QR yang akan menggunakan kamera smartphone untuk men-scan marker barcode pada brosur, About yang menjelaskan secara singkat mengenai aplikasi, dan Exit untuk keluar dari aplikasi.

\subsection{Implementation}

Pengumpulan data sangat penting dalam penelitian, karena data tersebut dimaksudkan untuk berkontribusi pada pemahaman kerangka teoretis yang lebih baik. Menentukan sampel dalam penelitian, terdapat teknik sampling yang digunakan salah satunya adalah teknik purposive sampling. Purposive sampling adalah teknik pengambilan sumber dengan pertimbangan tertentu. Misalnya akan melakukan penelitian tentang kualitas suatu makanan, maka sampel yang merupakan sumber data dari penelitian tersebut adalah orang yang ahli dalam makanan. Sampel 
ini digunakan untuk penelitian kualitatif atau penelitian-penelitian yang tidak melakukan generalisasi. Pemilihan informan dengan metode purposive sampling bertujuan untuk penelitian yang dilakukan peneliti akan mendapatkan capaian yang baik dan sesuai dengan keinginan informan. Pemilihan informan yang dilakukan peneliti dalam menganalisis assessment resiko pada sistem akademik online E-University yaitu memilih sumber data yang benar-benar bertanggung jawab atas sistem tersebut yaitu kepala UPT, Programmer dan Staf jaringan yang bertanggung jawab terhadap sistem.

\section{$2.4 \quad$ Integration Testing}

Seluruh unit yang dikembangkan dalam tahap implementasi diintegrasikan ke dalam sistem setelah pengujian yang dilakukan masing-masing unit. Setelah integrasi seluruh sistem diuji untuk mengecek setiap kegagalan maupun kesalahan.

\subsection{Integration \& Maintenance}

Tahap akhir dalam model waterfall. Perangkat lunak yang sudah jadi, dijalankan serta dilakukan pemeliharaan. Pemeliharaan termasuk dalam memperbaiki kesalahan yang tidak ditemukan pada langkah sebelumnya. Perbaikan implementasi unit sistem dan peningkatan jasa sistem sebagai kebutuhan baru (Rizal \& Sandiana, 2016).

\section{HASIL DAN PEMBAHASAN}

Penggunaan teknologi augmented reality sebagai inti dari teknologi yang diterapkan pada alat peraga, sehingga terdapat 2 bagian aplikasi yang harus dibuat yaitu marker sebagai landasan tempat lokasi munculnya augmented reality dan aplikasi mobile dengan isi konten produk elektronik (Arifitama, 2015). Berikut adalah penerapan yang dilakukan :

a. Marker

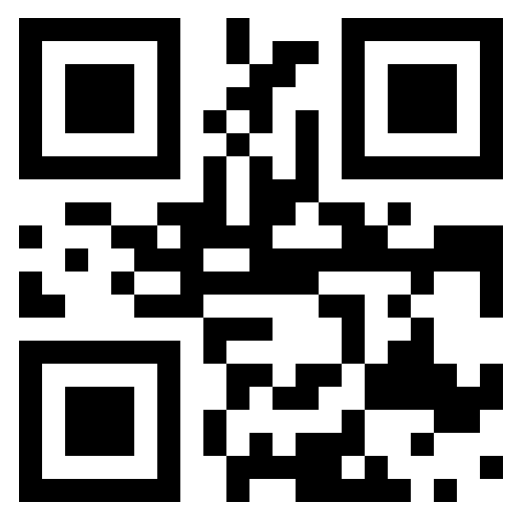

Gambar 2. Marker

Gambar diatas adalah marker berupa barcode yang terdapat di dalam brosur pemasaran. Pada saat marker tersebut di scan menggunakan kamera smartphone dan terdeteksi, maka akan muncul gambar produk elektronik dalam bentuk 3 dimensi. 
b. Brosur

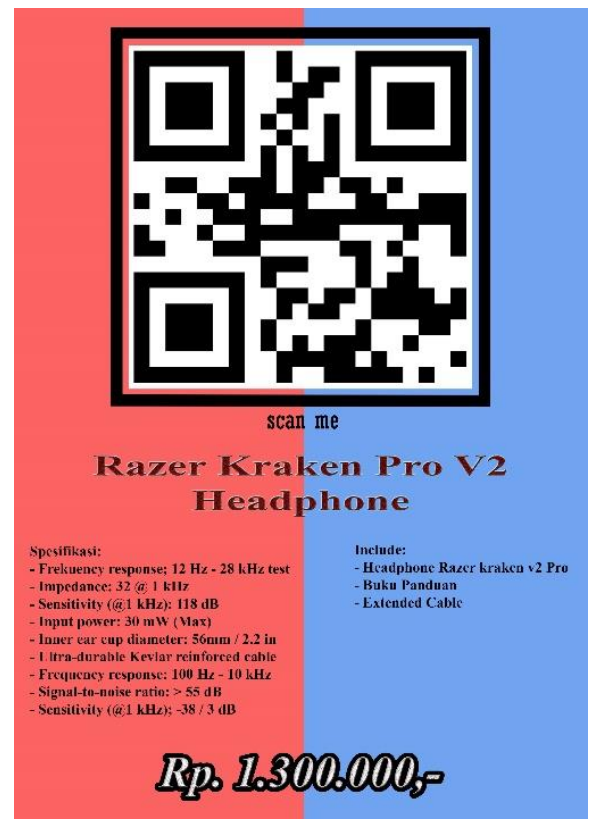

Gambar 3. Brosur

Gambar diatas adalah sebuah brosur untuk memasarkan produk, namun brosur tersebut menyediakan barcode untuk kemudian dapat di scan menggunakan kamera smartphone dan akan terdapat gambar produk elektronik secara 3 dimensi sesuai dengan informasi yang tertera di dalam brosur tersebut.

\section{c. Aplikasi}

1. Tampilan Awal

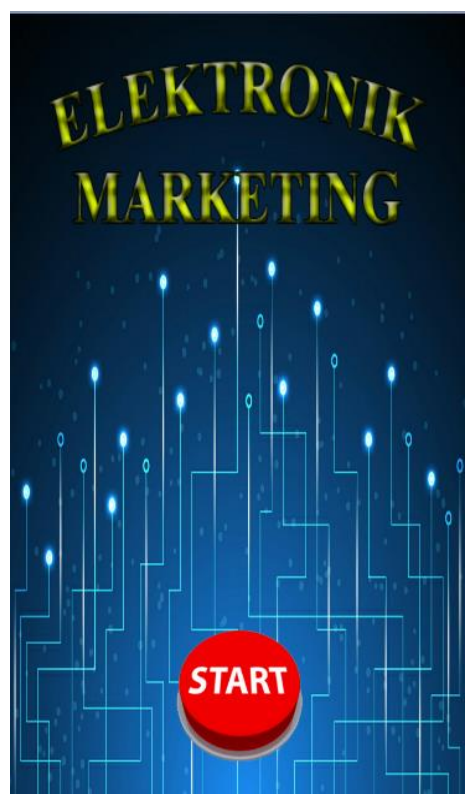

Gambar 3. Tampilan awal 
Gambar diatas adalah tampilan awal pada saat aplikasi dijalankan, hanya ada satu tombol yaitu tombol start. Jika tombol tersebut ditekan maka akan masuk ke dalam menu utama aplikasi tersebut.

2. Menu Utama

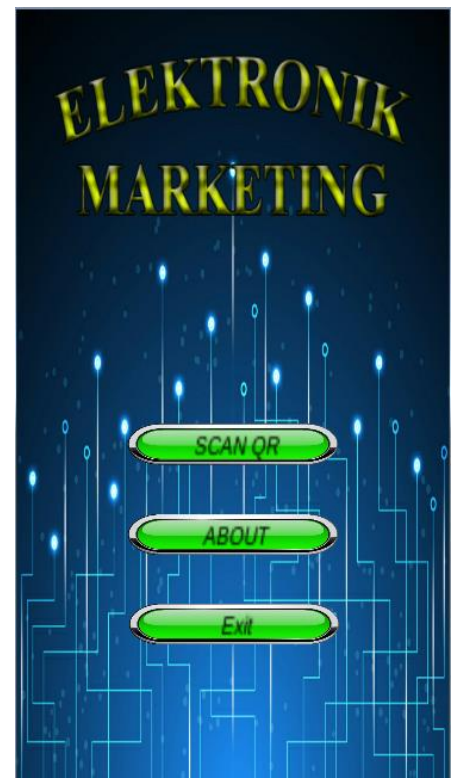

Gambar 4. Menu utama

Gambar diatas adalah tampilan menu utama pada aplikasi. Terdapat 3 menu yaitu Scan QR yang berguna untuk men-scan marker menggunakan kamera smartphone, About yang menjelaskan tentang aplikasi tersebut, dan Exit untuk keluar dari aplikas

\section{Scan $Q R$}

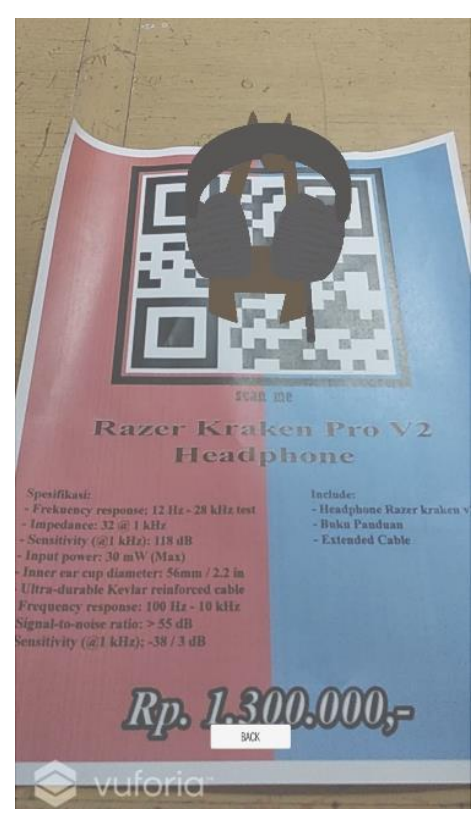

Gambar 5. Scan QR 
Gambar diatas merupakan hasil dari Scan QR pada brosur. Pada saat marker terdeteksi, maka akan muncul gambar produk secara 3 dimensi di bagian barcode. Lalu terdapat tombol back untuk kembali ke menu utama.

4. About

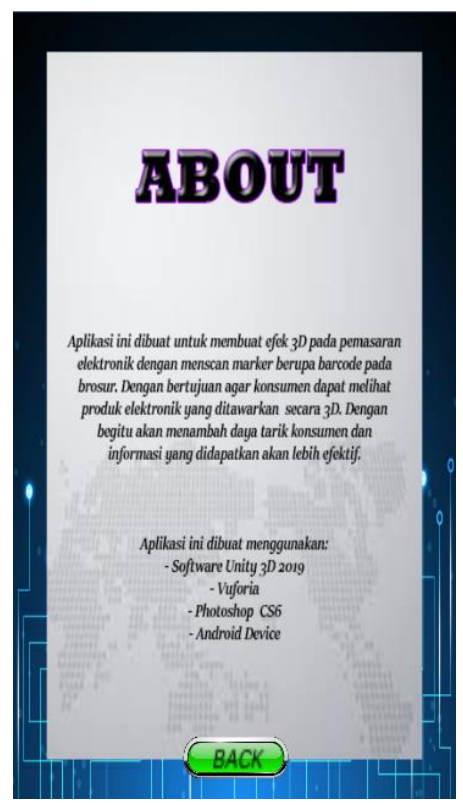

Gambar 6. About

Gambar diatas adalah tampilan About yang menjelaskan tentang aplikasi tersebut secara singkat. Lalu terdapat tombol BACK untuk kembali ke menu utama.

\section{KESIMPULAN}

Rancang bangun aplikasi pemasaran elektronik berbasis Augmented Reality ini dibuat menggunakan software Unity3D dan Vuforia SDK. Kemudian Photoshop CS6 sebagai alat bantu editor pada pembuatan brosur. Berdasarkan dari hasil penelitian yang dilakukan maka dapat disimpulkan sebagai berikut:

1. Dengan adanya aplikasi ini konsumen dapat melihat produk elektronik yang ditawarkan secara 3 dimensi sehingga konsumen mendapatkan penggambaran secara penuh dan juga dapat menambah daya tarik konsumen untuk membeli produk.

2. Aplikasi ini dapat menampilkan produk yang ditawarkan secara 3 dimensi dengan cara men-scan marker berupa barcode yang terdapat pada brosur pemasaran elektronik sehingga konsumen akan mendapatkan informasi produk secara lebih detail.

3. Aplikasi pemasaran elektronik ini memiliki beberapa kekurangan yaitu sebagai berikut:

- Tidak memiliki database yang terintegrasi langsung pada aplikasi

- Tidak memiliki aplikasi admin untuk mengelola secara langsung

- Menu pada aplikasi sangat terbatas 


\section{Referensi}

Anggratama, A. (2016). Augmented Reality Sebagai Media Pemasaran Di Dealer Auto 2000 Madiun. Jurnal TIKomSiN, 4, 1-7. https://p3m.sinus.ac.id/jurnal/index.php/TIKomSiN/article/view/264

Arifitama, B. (2015). Pengembangan Alat Peraga Pengenalan Tata Surya Bima Sakti Menggunakan Augmented Reality di PAUD. Sisfo, 05(04). https://doi.org/10.24089/j.sisfo.2015.09.006

Maulana, G. G. (2017). Penerapan Augmented Reality Untuk Pemasaran Produk Menggunakan Software Unity 3D Dan Vuforia. Jurnal Teknik Mesin, 6(2), 13. https://doi.org/10.22441/jtm.v6i2.1184

Rizal, M., \& Sandiana, L. (2016). Aplikasi Pemasaran Perumahan Berbasis Teknologi Augmented Reality. Inspiraton, 6, 140-147. https://doi.org/10.1080/10242694.2018.1477235

Wulandari, R., Setiawan, R., \& Mulyani, A. (n.d.). Perancangan Sistem Informasi Manajemen Wedding Organizer Online Menggunakan Scrum. 135-146. 